\title{
ANÁLISE DA GESTÃ O DA RESPONSABILIDADE SOCIAL INTERNA DE UMA EMPRESA DO TERCEIRO SETOR
}

\author{
ALINERI, Vivien ${ }^{53}$ \\ SILVA, Kelly Anne de Sousa ${ }^{54}$ \\ FARIA, Graciela Sanjutá Soares ${ }^{55}$
}

Recebido em: 2008-07-17

Aprovado em: 2008-08-04

Issue DOI: $10.3738 / 1982.2278 .118$

RESUMO: A responsabilidade social empresarial externa caracteriza-se pela participação direta nas ações comunitárias da região onde a empresa está inserida, apoiando assim o desenvolvimento da comunidade em geral. Já a responsabilidade social empresarial interna tem como foco o bem estar de seus funcionários e dependentes, de forma a levá-los a uma maior dedicação, empenho e lealdade, atingindo assim a máxima produtividade e qualidade dos serviços prestados. $O$ presente estudo buscou entender a gestão da responsabilidade social, em especial a interna, de uma empresa do terceiro setor. Para tanto, foi realizado um estudo de caso através da aplicação de questionários em seis funcionários de uma das unidades operacionais de uma organização não-governamental (ONG), situada na cidade de Franca-SP. Os dados mostraram que os participantes conhecem o tema "responsabilidade social" em suas duas principais vertentes, ou seja, responsabilidade social interna e externa, bem como consideram algumas práticas de responsabilidade social externa como sendo também responsabilidade social interna e identificam a gestão da responsabilidade social externa e interna na empresa em que trabalham.

Palavras-chave: Terceiro setor. Responsabilidade social. Responsabilidade social interna.

Funcionários.

\section{ANALYSIS OF MANAGEMENT OF SOCIAL RESPONSIBILITY OF AN INTERNAL COMPANY'S THIRD SECTOR}

SUMMARY: The corporate social responsibility it is characterized by direct participation in community actions in the region where the company is inserted, so supporting the development of the community in general. Already internal corporate social responsibility has as focus the welfare of its employees and dependents in order to lead them to greater dedication, commitment and loyalty, so reaching the highest productivity and quality of services provided. This study sought to understand the management of social responsibility, especially the

${ }^{53}$ Bacharel em Administração de Empresas com ênfase em Gestão de Negócios pela Fundação Educacional de Ituverava / Faculdade de Filosofia Ciências e Letras de Ituverava / Faculdade de Agronomia Dr Francisco Maeda

${ }^{54}$ Bacharel em Administração de Empresas com ênfase em Gestão de Negócios pela Fundação Educacional de Ituverava / Faculdade de Filosofia Ciências e Letras de Ituverava / Faculdade de Agronomia Dr Francisco Maeda

${ }^{55}$ Psicóloga, mestre e doutoranda pelo Programa de Engenharia de Produção da UFSCar (Universidade Federal de São Carlos) 
internal, a company in the third sector. To that end, a study was conducted in case of operating units of a nongovernmental organization (NGO), located in the city of Franca-SP, through the application of questionnaires in his six employees. The data showed that participants know the theme social responsibility in its two main components, namely internal and external social responsibility, identify the management of external and internal social responsibility in the company where they work, and consider some external practices of social responsibility as also internal social responsibility.

Keywords: Third Sector. Social responsibility. Internal social responsibility. Employees .

\section{INTRODUÇAO}

Não é de hoje que o comprometimento das empresas com ações socialmente responsáveis vem deixando o campo das intenções e está se fazendo visivelmente mais presente na realidade do mundo dos negócios. A partir da exigência dos consumidores, que estão cada vez mais conscientes da importância da participação das instituições privadas no desenvolvimento da sociedade, as organizações têm se mostrado cada vez mais engajadas em ações que geram sustentabilidade para a comunidade em que estão inseridas. Surge, assim, o terceiro setor empresarial, que tem como principal objetivo atuar no âmbito social, agindo em prol da sociedade a sua volta.

Segundo Melo Neto; Froes (2001), a responsabilidade social de uma empresa consiste na sua decisão de participar mais diretamente das ações comunitárias na região em que está presente, apoiando o desenvolvimento da comunidade, preservando o meio ambiente, investindo no bem estar dos seus funcionários e dependentes em um ambiente de trabalho saudável, além, é claro, de promover comunicações transparentes, dar retorno aos acionistas e assegurar sinergia com seus parceiros e garantir a satisfação dos seus clientes ou consumidores.

Dessa forma, o exercício empresarial pressupõe uma atitude eficaz da empresa em duas dimensões: a gestão da responsabilidade social interna e a externa. A responsabilidade social interna focaliza o público interno da empresa, ou seja, seus funcionários e respectivos dependentes. Já a responsabilidade social externa se concentra na comunidade mais próxima da empresa ou no ambiente em que ela está inserida (MELO NETO; FROES, 2001).

ssentido, propõe-se a seguinte questão para esta pesquisa: Será que as empresas do terceiro setor praticam responsabilidade social interna? Este trabalho objetiva compreender a responsabilidade social empresarial de uma empresa do terceiro setor, especialmente a interna, entendendo quais os mecanismos que as empresas desse setor, que se caracterizam por serem responsáveis com a sociedade, utilizam na responsabilidade social com seus 
funcionários e dependentes.

Vale ressaltar que não são muitos os estudos voltados para a análise da responsabilidade social interna e que este trabalho poderá ajudar a entender e criar um parâmetro que possa servir para essa ou outra organização do setor que se interessar em fazer uso dos conceitos de gestão da responsabilidade social interna.

Utilizando a literatura específica sobre o tema, será feita uma síntese bibliográfica sobre responsabilidade social empresarial e o terceiro setor. Em seguida, será apresentado o método de pesquisa, os resultados do estudo de caso realizado em uma organização nãogovernamental (ONG) e a contrapartida entre os conceitos e os resultados do estudo de caso.

\section{RESPONSABILIDADE SOCIAL EMPRESARIAL E OTERCEIRO SETOR}

A ética da responsabilidade social surgiu primeiro na Europa e os seus adeptos sofreram muita discriminação e boicote. A ONU (Organização das Nações Unidas), por meio de suas resoluções referentes ao "Apartheid", nos anos 70, foi que contribuiu para uma melhor conscientização a respeito. Hoje o fenômeno da responsabilidade social é global, não mais centralizado onde iniciou (NADAS, 2001).

O terceiro setor é constituído por organizações sem fins lucrativos e nãogovernamentais que surgiram para suprir as necessidades do âmbito social, que o primeiro setor, estado, não consegue manter. $\mathrm{O}$ conjunto desse tipo de organização forma um grupo social que interage entre si e compartilha dos mesmos valores e crenças. Com isso, a criação de institutos e fundações está se tornando, atualmente, uma prática corriqueira entre as grandes empresas do Brasil. A finalidade dessas instituições é profissionalizar os investimentos sociais de suas mantenedoras para a comunidade externa (MELO NETO; FROES, 2001).

Segundo Fabião (2003), o que se chama de terceiro setor pode ser subdividido em três grupos: comunitário, empresarial e governamental. O terceiro setor comunitário seria representado pelas ONG's, o terceiro setor empresarial por instituições e fundações mantidas pelo empresariado com a intenção de promover sua imagem social e já o terceiro setor governamental, por organizações da sociedade cível, que executam políticas públicas.

Para atuar no setor social, as empresas do segundo setor precisam mudar o foco que deixa de ser o lucro e passa a ser o fator humano. O desafio para essas empresas é desenvolver mecanismos de interação democrática com seus parceiros estratégicos (FABIÃO, 2003). 
A distância entre as vontades da empresa e as necessidades da comunidade é o principal indício de que as práticas de responsabilidade social precisam avançar e muito. Entretanto, a principal medida para as empresas brasileiras se tornarem socialmente responsáveis é serem mais transparentes, uma vez que somente medidas de marketing social não resolvem problemas sociais. A consciência deve nascer e ser posta em prática próativamente (FABIÃO, 2003).

Nadas (2001) constatou que o assunto "ética nos negócios" e "responsabilidade social" estão em evidência nos EUA, há mais de 30 anos, e apresentam crescimento, não se tratando de modismo. Para essa afirmação, ele tem como base duas pesquisas realizadas nos EUA, pela revista Newsweek, e outra realizada pela Fundação Príncipe de Gales, no Reino Unido.

A pesquisa feita pela revista Newsweek, em parceria com a organização Harris, ocorrida em 1999 e 2000, questionava o seguinte: as empresas devem apenas preocupar-se com seus lucros ou devem se preocupar também com a comunidade, podendo até sacrificar seus lucros? Dos entrevistados, 95\% disseram que as empresas devem ter uma responsabilidade social, além de buscar lucros (NADAS, 2001).

Na pesquisa da Fundação Príncipe de Gales, foram propostas para 25.000 pessoas a seguinte questão: a empresa deveria ter qual finalidade? Dois terços dos entrevistados foram favoráveis à responsabilidade social, além dos lucros. Apesar de ainda ser o principal fim da empresa, o lucro vem, cada vez mais, dando espaço para os fins sociais (NADAS, 2001).

Segundo Caetano; Ashley; Giansanti (2006), no Brasil o movimento de valorização da responsabilidade social empresarial ganhou forte impulso, na década de 90, através da ação de entidades não-governamentais, institutos de pesquisa e empresas sensibilizadas para a questão.

As enormes carências e desigualdades sociais existentes em nosso país dão à responsabilidade social empresarial relevância ainda maior. A sociedade brasileira espera que as empresas cumpram um novo papel no processo de desenvolvimento, isto é, sejam agentes de uma nova cultura, atores de mudança social e construtores de uma sociedade melhor (CAETANO; ASHLEY; GIANSANTI, 2006).

O conceito de responsabilidade social para alguns é a obrigação social da empresa, para outros é o comportamento social responsável no âmbito da ética e para outros ainda é apenas as ações de caridade que a empresa tem. No entanto, responsabilidade social é um misto de tudo isso, ainda que seja de cunho ideológico, ou seja, ainda encontra limites entre a ética e a moral (NADAS, 2001). 
A empresa demonstra sua responsabilidade social ao comprometer-se com programas sociais voltados para o futuro da comunidade e da sociedade. O investimento em processos produtivos compatíveis com a conservação ambiental e a preocupação com o uso racional dos recursos naturais também têm importante valor simbólico, por serem de interesse da empresa e da coletividade. Com iniciativas desse tipo, a empresa revela sua crença no preceito de que só uma sociedade saudável pode gerar empresas saudáveis (CAETANO; ASHLEY; GIANSANTI, 2006).

Empresas socialmente responsáveis estão mais bem preparadas para assegurar a sustentabilidade a longo prazo nos negócios por estarem sincronizadas com as novas dinâmicas que afetam a sociedade e o mundo empresarial. O necessário envolvimento de toda a organização na prática da responsabilidade social gera sinergias, principalmente com os públicos dos quais ela tanto depende, e fortalecem seu desempenho global (CAETANO; ASHLEY; GIANSANTI, 2006)

Contudo, segundo Montana e Charnov (1998), há autores que são contrários a qualquer ação empresarial que não seja voltada aos interesses econômicos da empresa, argumentando que, ao agir de forma contrária a isso, a empresa estaria lesando seus acionistas. Além disso, estes mesmos autores argumentam não existirem razões para se acreditar que empresários tenham habilidade para atingir as metas sociais. Para eles, a empresa é socialmente responsável quando gera lucro, pois assim consegue gerar empregos, pagar salários justos, contribuindo assim para melhora na vida de seus funcionários, que por sua vez pagarão em dia seus impostos, contribuindo para o bem estar público. Diante do exposto, pode-se concluir que existem autores que vêem a responsabilidade social como secundária e espontânea, sendo conseguida com a lucratividade da empresa.

\section{RESPONSABILIDADE SOCIAL EXTERNA E INTERNA}

A responsabilidade social empresarial externa ultrapassa os limites das relações da empresa com seus funcionários, reforçando assim seu relacionamento com fornecedores, consumidores, comunidade e com o meio ambiente (OLIVEIRA; SCHWERTNER, 2007).

Em relação aos fornecedores e consumidores, a empresa deve buscar a colaboração para a diminuição dos custos e maior qualidade dos produtos e serviços prestados. No que diz respeito à comunidade, a empresa tem que se preocupar em atender a carência de cada lugar, fazendo doações às obras beneficentes e ajudando na implantação de centros comunitários que integrem à empresa na comunidade (OLIVEIRA; SCWERTNER, 2007). 
As empresas alegam que a motivação para investirem em projetos sociais na comunidade externa é o compromisso ético que elas possuem com o desenvolvimento da sociedade. No entanto, a ética, antes de ser um tema inerente ao negócio, ainda é entendida como mais um recurso a ser utilizado para se atingir os objetivos empresarias. Sendo assim, a responsabilidade social das empresas parece se referir mais ao impacto nos negócios (MELO NETO; FROES, 2001).

A empresa é socialmente responsável quando vai além da obrigação de respeitar as leis, pagar impostos e observar as condições adequadas de segurança e saúde para os funcionários, fazendo isso por acreditar que assim será uma empresa melhor e estará contribuindo para a construção de uma sociedade mais justa (CAETANO; ASHLEY; GIANSANTI, 2006).

A prática da responsabilidade social revela-se internamente na constituição de um ambiente de trabalho saudável e propício à realização profissional das pessoas. Com isso, a empresa aumenta sua capacidade de recrutar e manter talentos, fator chave para seu sucesso numa época em que criatividade e inteligência são recursos cada vez mais valiosos (CAETANO; ASHLEY; GIANSANTI, 2006).

Em se tratando especificamente de responsabilidade social empresarial interna, o Instituto Ethos de Responsabilidade Social Empresarial (2007) diz que:

\begin{abstract}
A empresa socialmente responsável não se limita a respeitar os direitos dos trabalhadores, consolidados na legislação trabalhista e nos padrões da OIT (Organização Internacional do Trabalho), ainda que esse seja um pressuposto indispensável. A empresa deve ir além e investir no desenvolvimento pessoal e profissional de seus empregados, bem como na melhoria das condições de trabalho e no estreitamento de suas relações com os empregados. Também deve estar atenta para o respeito às culturas locais, revelado por um relacionamento ético e responsável com as minorias e instituições que representam seus interesses.

(INSTITUTO ETHOS..., 2007).
\end{abstract}

As ações de gestão de responsabilidade social interna compreendem os programas de contratação, seleção, treinamento e manutenção de pessoal, que são realizados pelas empresas em benefício de seus funcionários, bem como os demais programas de benefícios voltados para a participação nos resultados e atendimento aos dependentes (MELO NETO; FROES, 2001).

A responsabilidade social interna focaliza os seus colaboradores e seus dependentes. $\mathrm{O}$ seu objetivo é motivá-los para um desempenho ótimo, criar um ambiente de trabalho favorável e contribuir para seu bem estar. Com isso, a empresa ganha dedicação, empenho e lealdade, podendo trazer ganhos de produtividade enormes (MELO NETO; FROES 2001). 


\section{METODOLOGIA}

\subsection{PARTICIPANTES}

Todos os funcionários da unidade operacional de uma ONG, Organização NãoGovernamental, situada na cidade de Franca - SP. Dentre os seis participantes, cinco eram mulheres e três eram casados, com média de idade de 31 anos, sendo o mínimo de 21 anos e o máximo de 61 anos. Relativo aos cargos, dois são estagiários, dois são assistentes de relação externa, um auxiliar de desenvolvimento estudantil e um supervisor. A média de tempo na empresa era de 46 meses, valendo ressaltar que existem funcionários com apenas dois meses na empresa e outros com até 87 meses. O nível de escolaridade de três deles é superior completo, de dois superior incompleto e um cursou pós-graduação.

\subsection{PROCEDIMENTO}

Foi feito um estudo de caso em uma ONG que é a maior da América Latina, está há mais de 40 anos no mercado e contém mais de 200 unidades espalhadas pelo país. Esta ONG tem como propósito a interação entre empresas e escolas para a inserção do jovem estudante no mercado de trabalho através do programa de estágio, além de ter vários outros projetos sociais.

Para o desenvolvimento do estudo, foi aplicado um questionário nos seis únicos funcionários de uma unidade da ONG em questão. O questionário continha 18 perguntas, sendo 11 envolvendo aspectos pessoais e profissionais dos participantes e as sete restantes questionavam sobre: os benefícios oferecidos pela empresa, se esses benefícios são vistos como práticas de responsabilidade social interna, se os funcionários sentem-se protegidos socialmente dentro da empresa, se os programas de responsabilidade social externa promovido pela empresa os fazem sentirem também socialmente responsáveis e, por último, a sua compreensão de responsabilidade social. 


\section{ANÁLISE DA RESPONSABILIDADE SOCIAL INTERNA EM UMA EMPRESA DO TERCEIRO SETOR}

São apresentados os resultados referentes ao estudo de caso realizado a partir da aplicação dos questionários em seis funcionários. A seguir, encontram-se dados sobre:

- os benefícios oferecidos,

- as oportunidades de crescimento e desenvolvimento dentro da empresa,

- as práticas sociais internas,

- a proteção social,

- os benefícios como responsabilidade social interna,

- o envolvimento dos funcionários nas práticas sociais externas desenvolvidas pela empresa,

- as práticas de integração entre os funcionários como práticas de responsabilidade social interna

- como os funcionários entendem o tema responsabilidade social.

Os funcionários, ao serem questionados sobre os benefícios que a empresa oferece, destacaram por frequência de aparecimento, respectivamente: o vale alimentação, o convênio médico, o vale transporte, o convênio odontológico, o auxílio creche, o cartão farmácia, entre outros benefícios, conforme pode ser visto na tabela 1 .

Tabela 1 - Benefícios Oferecidos pela Empresa

\begin{tabular}{c|c|c}
\hline Benefícios & $\begin{array}{c}\text { Freqüência absoluta } \\
(\mathbf{n = 3 0})\end{array}$ & $\begin{array}{c}\text { Freqüência relativa } \\
(\mathbf{\%})\end{array}$ \\
\hline Vale alimentação & 6 & $20 \%$ \\
\hline Convênio médico & 4 & $13,33 \%$ \\
\hline Vale transporte & 3 & $10 \%$ \\
\hline Convênio odontológico & 3 & $10 \%$ \\
\hline Auxílio creche & 3 & $10 \%$ \\
\hline Cartão farmácia & 3 & $10 \%$ \\
\hline Auxílio funerário & 2 & $6,66 \%$ \\
\hline Incentivo a educação & 2 & $6,66 \%$ \\
\hline Seguro de vida & 2 & $6,66 \%$ \\
\hline $14^{\circ}$ Salário & 1 & $3,33 \%$ \\
\hline Seguro do veículo & 1 & $3,33 \%$ \\
\hline
\end{tabular}

* Para todos os resultados fornecidos, $\mathrm{n}$ corresponde ao número total de respostas originadas para cada uma das questões e não ao número de questionados repondentes, pois, para a grande maioria das questões os funcionários deram mais de uma resposta. 
Quanto às oportunidades de crescimento, desenvolvimento e segurança no emprego, cinco dos seis funcionários disseram visualizar essas oportunidades, inclusive um deles, quando questionado citou que:

"Com toda a certeza, pois é uma empresa que oferece um plano de carreira, a se ver pela unidade de Franca onde das cinco colaboradoras, três eram estagiárias e foram efetivadas."

Referente às práticas sociais internas desenvolvidas pela empresa, os respondentes, quando indagados, ressaltaram práticas como: incentivo à educação $(\mathrm{n}=2)$, incentivo à inserção de portadores de necessidades especiais no mercado de trabalho $(n=2)$, integração empresa $x$ estudante $(n=1)$ e respeito por parte da empresa às 8 metas do milênio ${ }^{56}(n=1)$.

Práticas como incentivo à educação $(n=3)$, qualidade de vida/cidadania $(n=2)$ e respeito aos direitos dos funcionários $(n=1)$ foram citados como benefícios que evidenciam a responsabilidade social interna. Um deles ressaltou que:

"Os funcionários que possuem mais de seis meses de registro e ainda não possuem graduação, é lhes oferecido um incentivo de até $80 \%$ do valor da mensalidade”.

Em se tratando da proteção social dos funcionários dentro da empresa, eles destacaram práticas como: campanhas de ação social $(n=3)$, valorização do funcionário $(n=2)$ e espírito de equipe $(n=1)$. Um dos entrevistados comentou que:

"A empresa oferece benefícios e promove campanhas que estimulam minha ação social como indivíduo”.

Quanto ao envolvimento dos funcionários nas ações de responsabilidade social da empresa com a sociedade, foi destacado por cinco respondentes, os projetos sociais. Um dos

\footnotetext{
${ }^{56}$ As oito metas do milênio designadas pela ONU (Organização das Nações Unidas) são:

1. Acabar com a fome e a miséria

2. Educação básica e de qualidade para todos

3. Igualdade entre sexos e valorização da mulher

4. Reduzir a mortalidade infantil

5. Melhorar a saúde das gestantes

6. Combater a AIDS, a malária e outras doenças

7. Qualidade de vida e respeito ao meio ambiente

8. Todo mundo trabalhando pelo desenvolvimento
} 
funcionários chamou a atenção para a falta de divulgação interna dessas ações, conforme o relato a seguir:

\footnotetext{
"Apenas acho que a empresa deveria não apenas dar satisfação a sociedade sobre suas ações sociais, mas a todos nós colaboradores antes de mais nada".
}

A empresa possui um coral formado por seus funcionários e quando questionados se essa prática caracterizava-se como responsabilidade social interna da empresa, os seis entrevistados responderam afirmativamente e um deles ainda ressaltou que:

“Com certeza, pois a música é a essência da expressão da beleza, da integração entre as pessoas e, por conseguinte, totalmente inserida na responsabilidade social".

Quando questionados sobre como definiriam responsabilidade social, os respondentes mencionaram: co-responsabilidade com a sociedade $(n=4)$, garantia do bem estar interno e externo da empresa $(n=1)$ e a integração das pessoas na sociedade $(n=1)$. Um deles fala da coresponsabilidade com a sociedade da seguinte maneira:

"Para mim, responsabilidade social é conduzir minhas ações e atitudes, e no caso da empresa, suas atividades, de maneira que eu me sinta co-responsável pelo envolvimento da sociedade na qual estou inserida”.

\section{CONCLUSÃO}

Pode-se entender que a gestão de responsabilidade social ainda está em expansão no Brasil e no mundo, existindo divergências entre os autores que discutem esse tema. Para uns, responsabilidade social se resume apenas na geração dos lucros pois, dessa maneira, podem pagar em dia seus funcionários, que por sua vez, pagam em dia seus impostos, gerando assim o bem estar público. Para outros, a responsabilidade social vai muito além dos limites da empresa, atingindo a sociedade de um modo geral, o meio ambiente e o local onde a empresa está situada. Em se tratando de responsabilidade social interna, a discussão é ainda mais ampla, chegando até a serem citados os dependentes dos funcionários como beneficiários.

Com os resultados obtidos no estudo de caso, percebeu-se que os funcionários da organização não-governamental, cujo foco é a responsabilidade social, identificam suas 
práticas de responsabilidade social interna. As oportunidades de crescimento dentro da empresa são confirmadas por cinco dos seis respondentes e eles mencionam, como práticas de responsabilidade social interna da empresa que trabalham, o incentivo à educação, o programa desenvolvido para inserção de portadores de necessidades especiais no mercado de trabalho, a integração empresa-escola e a atenção com as oito metas do milênio.

É interessante notar que eles destacaram as ações sociais desenvolvidas com o público externo como uma forma de gestão de responsabilidade social interna, já que se sentem também co-responsáveis pela sociedade. Assim, percebe-se que na perspectiva dos participantes a responsabilidade social interna e externa se misturam e são interdependentes.

Um programa de responsabilidade social interna para ser bem sucedido deve contar com a opinião e participação direta dos seus funcionários. Um dos respondentes disse faltar uma maior divulgação interna das práticas sociais externas realizadas pela empresa e isso deve ser considerado e analisado pelos tomadores de decisão dela.

Diante do exposto, compreende-se que o tema "responsabilidade social empresarial", apesar de ainda parecer de cunho ideológico, está em expansão, e a sociedade tem-se mostrado mais aberta a conhecer, aprofundar em suas práticas e ser socialmente responsável de alguma maneira, seja do modo mais simples, pagando em dia seus impostos, ou até de uma forma mais complexa, ampliando o plano de benefícios dos funcionários e chegando a atingir até seus dependentes.

\section{REFERÊNCIAS}

CAETANO, G; ASHLEY, P; GIANSANTI, R. Responsabilidade social e meio ambiente; edição customizada; São Paulo: Saraiva, 2006.

CORREIA, F. T. de B. S; MEDEIROS, J. R. C. Responsabilidade Social Corporativa para quem? Responsabilidade social das empresas: a contribuição das universidades. Publicação $2^{\circ}$ Edição Prêmio Ethos Valor, v2; São Paulo: Peirópolis 2003. p. 151-199

FABIÃO, M. F. O Negócio da ética: um estudo sobre o terceiro setor empresarial. Responsabilidade social das empresas: a contribuição das Universidades; Volume 2; São Paulo: Peirópolis 2003. p. 43-75. (Publicação $2^{\circ}$ Edição Prêmio Ethos Valor).

INSTITUTO ETHOS DE EMPRESAS E RESPONSABILIDADE SOCIAL. Indicadores ethos de responsabilidade social empresarial. São Paulo, 2007. Disponível em http://www.ethos.org.br/docs/conceitos_praticas/indicadores/temas/publico_interno.asp . 
Acesso em 10 ago. 2007.

MONTANA, P. J ; CHARNOV, B. H. Administração. São Paulo: Saraiva, 1998.

NADAS, P. Ética nos negócios: a quantas andamos? Reflexões sobre uma palestra ministrada em 24/04/2001 pela professora Laura Nash - Universidade de Harvard. Disponível em: http://www.fides.org.br/artigo02.pdf . Acesso em: 11 nov. 2006

MELO NETO, F. P. de; FROES, César. Gestão da responsabilidade social corporativa: O caso brasileiro; 2. ed. Rio de Janeiro: QualityMark, 2001. 229p.

OLIVEIRA, L. J. de; SCHWETNER, I. M. G. Breve análise das práticas de responsabilidade social empresarial e a concessão de incentivos governamentais. Disponível em: http://jus2.uol.com.br/doutrina/texto.asp?id=9864 . Acesso em 29 ago. 2007 